\title{
CBCT Evaluation of Changes in Root Canal Geometry Induced by the Chemical Structure of NiTi Alloys of Three Rotary Systems
}

\author{
SANDA ILEANA CIMPEAN ${ }^{1}$, ADRIAN MIHAI VARVARA ${ }^{2}$, \\ SMARANDA DANA BUDURU ${ }^{3 *}$, IOANA SOFIA CIUTRILA ${ }^{\mathbf{1}}$, \\ MIHAELA CARMEN HEDESIU ${ }^{4}$, ANCA CIUREA ${ }^{5}$, \\ LOREDANA ADELA COLCERIU BURTEA ${ }^{1}$
}

${ }^{1}$ Iuliu Hatieganu University of Medicine and Pharmacy, Department of Conservative Dentistry and Endodontics, Faculty of Dental Medicine, 33 Motilor Str., 400001, Cluj-Napoca, Romania

${ }^{2}$ Iuliu Hatieganu University of Medicine and Pharmacy, Department of Propaedeutics and Dental Aesthetics, Faculty of Dental Medicine, 32 Clinicilor Str., 400006, Cluj-Napoca, Romania

${ }^{3}$ Iuliu Hatieganu University of Medicine and Pharmacy, PhD, Department of Prosthodontics, Faculty of Dental Medicine, 32 Clinicilor Str., 400006, Cluj-Napoca, Romania

${ }^{4}$ Iuliu Hatieganu University of Medicine and Pharmacy, Department of Radiology, Faculty of Dental Medicine, 32 Clinicilor Str., 400006, Cluj-Napoca, Romania

${ }^{5}$ Iuliu Hatieganu University of Medicine and Pharmacy, Department of Radiology, Faculty of Medicine, 3-5 Clinicilor Str., 400006, Cluj-Napoca, Romania

\begin{abstract}
Preservation of the root canal anatomy is very important for the success of endodontic treatment.Properly instrumentation of curvet root canals is influenced by flexibility of endodontic instruments which depends on composition and thermomechanical treatment of the metallic alloy. The aim of the current study was to compare the changes in root canal geometry after the preparation with two systems that work in reciprocating motion (Reciproc25, Primary Wave One) and another one in continuous rotation (One Shape), using CT measurements. Forty-five canals of extracted molars with curvatures ranging from 9 to 40 degrees were chosen for this study. The canals were divided, according to the canal curvature into three homogeneous groups and were prepared with three different rotary systems: group I with Reciproc file 25.08 (VDW, Munich, Germany), group II with Wave One Primary 25.08 (Dentsply-Maillefer Ballaigues, Switzerland) and group III with One Shape 25.06 (Micro Méga, Bensançon, France).All groups were scanned pre and post instrumentation, using NewTo $3 G$ CBCT (QR, Italy, FOV, 0.16mm voxel size). The following parameters were assessed after measurements on cross-sectional CBCT images: the centering ability, diameter change, canal transportation. All instruments maintain the original canal curvature well, resulting in no significant differences of their centering ability $(P>0.05)$ and canal transportation $(P>0.05)$. The highest increase in diameter of canal was observed with Primary Wave One, which was not statistically significant for the entire canal $(P>0.05)$. Instrumentation with Reciproc was faster than instrumentation with One Shape and Wave One,but the differences were not statistically significant $(P>0.05)$. All systems perform safe and proper canal preparations and can be used in root canal treatment of curved canals.
\end{abstract}

Keywords: Canal transportation, Centering ability, One Shape, Reciproc, Wave One

\section{Introduction}

Root canal shaping is a predictive factor for the success of endodontic treatment and tends to preserve the integrity and location of the canal and apical anatomy [1,2]. With the introduction of root canal instruments made of the highly elastic nickel-titanium alloy, the technical quality of root canal preparation has been steadily improving during the past years [3]. However, since these techniques also require the use of numerous instruments to enlarge the canal to an adequate size and taper, they are relatively time consuming [4].

\footnotetext{
*email: smarandabuduru@yahoo.com
} 
G. Yared [5] recently introduced a new concept for canal preparation which requires the use of only one specific instrument in reciprocating motion for the enlargement of canals, including narrow and curved canals (the Reciproc system VDW, Munich, Germany). Another system used in reciprocating motion is WaveOne (Dentsply Maillefer, Ballaigues, Switzerland). These systems are available in various designs and sizes and present the different values of a counter clockwise and clockwise rotation. These files are made of a new variant NiTi alloy called M-Wire that has increased flexibility of the instruments and improved resistance to cyclic fatigue [6, 7].

The reciprocating instruments offer many advantages over nickel titanium rotary instruments: the working time is shorter [3] , the canal centering ability is enhanced, leading to less invasive root canal preparations [1] This technique is safer than the rotary technique because fracture by binding is eliminated and the cyclic fatigue resistance in reciprocating motion is higher than in the case of continuous rotation [8] The single use of endodontic instruments eliminates possible crosscontamination, provides a reduced instrument fatigue and is more cost-effective $[4,9]$.

Another concept of single file instrumentation uses a continuous rotation for root canal shaping. This is the One Shape system that consists of only one instrument with a tip size of 25 and a constant taper of 0.06 , and is characterized by different cross sectional designs across the entire length of the working part. It is made of conventional austenite 55- NiTi alloy and its rotational speed is $400 \mathrm{rpm}$ while its torque is $2.5 \mathrm{~N} / \mathrm{cm}^{2}$ (as recommended by the manufacturer) [10]

Previous studies have shown that root canal shaping with a reciprocating single file can be performed with a good centering ability in curved canals [1,2,11], but still there are few studies on continuous single file systems [12]. Some studies analyzed the modification of the canal curvature after preparation of the curved canal in Endo Training Blocks with Wave One system [1,2] by superimposing photographic images, whilst others compared shaping ability of Wave One and Reciproc systems after instrumentation of curved root canals by assessment of standardized radiographs $[11,12]$.

Gambill [13] used CBCT to evaluate the changes of root canal anatomy after instrumentation. This comparison using computed tomography has provided a reproducible means of various aspects of endodontic instrumentation.

The aim of the current study was to compare the changes in root canal geometry after the preparation with two systems that work in reciprocating motion (Reciproc 25, Primary Wave One) and one made in conventional $\mathrm{NiTi}$ that works in continuous rotation (One Shape), using CT measurements.

\section{Materials and methods}

\subsection{Sample preparation}

This study was approved by the Ethics Board of the local University (protocol number 350)

Forty-five curved canals of extracted maxillary and mandibular molars were included in the study. Tissue fragments and calcified debris were removed from teeth by scaling After preparation of the access cavity, using diamond burs, the canals were controlled for apical patency with a MMC file 10 (Micro Méga, Bensançon, France). Teeth that did not allow the scouting with $10 \mathrm{MMC}$ file to the apical foramen were removed. The standardized radiographs were taken using X-Mind ${ }^{\mathrm{TM}} \mathrm{DC}$ (Satelec, Merignac, France)with the initial file insert in the canal from the buccal and proximal aspects in order to determine the root canal curvature. The root curvature was quantified, using Schneider criteria [14]. On the basis of the preoperative measuring of the curvature angle, 45 canals (curvatures ranging from 9-40 degrees) were allocated into one of three groups. The homogeneity of the groups was assessed using $t$ Test (Table 1). Only the teeth with intact root apices and with the root canal width at the apex compatible with size 10 were included. 


\begin{tabular}{ccc}
\hline & \multicolumn{2}{c}{ Curvature (degrees) } \\
Instrument & Mean & SD \\
\hline Wave One & 18.71 & \pm 8.93 \\
Reciproc & 21.08 & \pm 12.47 \\
One shape & 18.85 & \pm 9.48 \\
\hline
\end{tabular}

\author{
Table 1. Mean of \\ degree of curvature of \\ root canals $(n=15)$
}

The teeth were placed, with long axis of the root in vertical position, into a $20 \mathrm{X} 100 \mathrm{~mm}$ plastic dish and acrylic resin (Vertex-Dental B.V.H J Zeist, The Netherlands) was purred over them until a height of $2.5 \mathrm{~mm}$. Only the coronal part of the teeth was introduced in this support. This set was used to ensure precise positioning of the teeth into the scanning system for both scans.

The WL of each canal was calculated to be $1 \mathrm{~mm}$ less than the length obtained with a size $10 \mathrm{~K}$-file that was insert into the canal until it was visible at the apical foramen.

At the beginning of the treatment the root canals were lubricated with Endoprep$\mathrm{MM}^{{ }^{\circledR *}}$ (MicroMéga Besançon, France). After each insertion of the rotary instrument the canal was irrigated with $1 \mathrm{~mL} \mathrm{NaOCl} \mathrm{5.25 \%} \mathrm{(Cloraxid,} \mathrm{Cerkamed,} \mathrm{Stalowa} \mathrm{Wola} \mathrm{Poland)} \mathrm{solution} \mathrm{using} \mathrm{a}$ plastic syringe with Endo-Top needle (0.3x 25) ( Cerkamed, Stalowa Wola, Poland ).

The canals were prepared with three different rotary systems as follows:

Group I ( $\mathrm{n}=15)$ without creating the glide path, a R25 Reciproc file (25.08) (VDW, Munich, Germany) was used.

Group II ( $\mathrm{n}=15)$ without creating the glide path, a Wave One Primary (25.08) (Dentsply-Maillefer Ballaigues, Switzerland) was used.

Group III ( $\mathrm{n}=15)$ without creating the glide path, a One Shape (25.06) (MicroMéga, Bensançon, France) was used (Table 2).

Table 2. Chemical structure of NiTi files

\begin{tabular}{ccc}
\hline Instrument & Alloy & $\begin{array}{c}\text { Thermomechanical } \\
\text { treatment }\end{array}$ \\
\hline Wave One & M-wire & Yes \\
Reciproc & M-wire & Yes \\
One shape & NiTi 55/45 & No \\
\hline
\end{tabular}

Reciproc and Wave One Primary were used in a reciprocating working motion and One Shape into permanent rotation (at $400 \mathrm{rtm}$ and the torque at $2.5 \mathrm{~N} . \mathrm{cm}$ ) generated by the Silver Reciproc motor (VDW GmbH, Munich, Germany) according to the manufacturer's instructions.

For each group after three in-and-out movements, the instrument was removed from the canal and the flutes of the instrument were cleaned. Each instrument was changed after four canals only.

All root canal preparations were performed by one operator.

\subsection{CBCT scanning}

All groups were scanned pre and post instrumentation, using NewTom 3G CBCT (QR, Italy, FOV, $0.16 \mathrm{~mm}$ voxel size). The acrylic support was placed in the same orientation into the device for both scans. The slice data from the scan was archived on a computer. The same computer settings and viewing parameters were used to analyze both uninstrumented and instrumented images. 


\subsection{Data analysis}

The cross-sectional images perpendicular to the long axis of the teeth were obtained starting at $1 \mathrm{~mm}$ from the apex up to the coronal orifice. Horizontal sections were made perpendicular to a vertical line that was drawn from the same point for both scans. Distance between sections was $1 \mathrm{~mm}$. The first nine levels were chosen for CT evaluation (Figure1 upper panel).

For each group the cross-sectional images, at the same level, were superimposed using the external circumference of the root as reference and compared by using Adobe Photoshop software (S5C version). In order to superimpose the 2 images, one of them underwent a slight lightening, which allowed a clear observation of the circumference of the second one. Following superimposing, a line was drawn over the pictures crossing the centre of the canal and then the images were deferred. At the level of this line a second examiner, who was blind with regards to the experimental groups assessed the wall size prior to and after instrumentation (Figure 1 middle and lower panels).

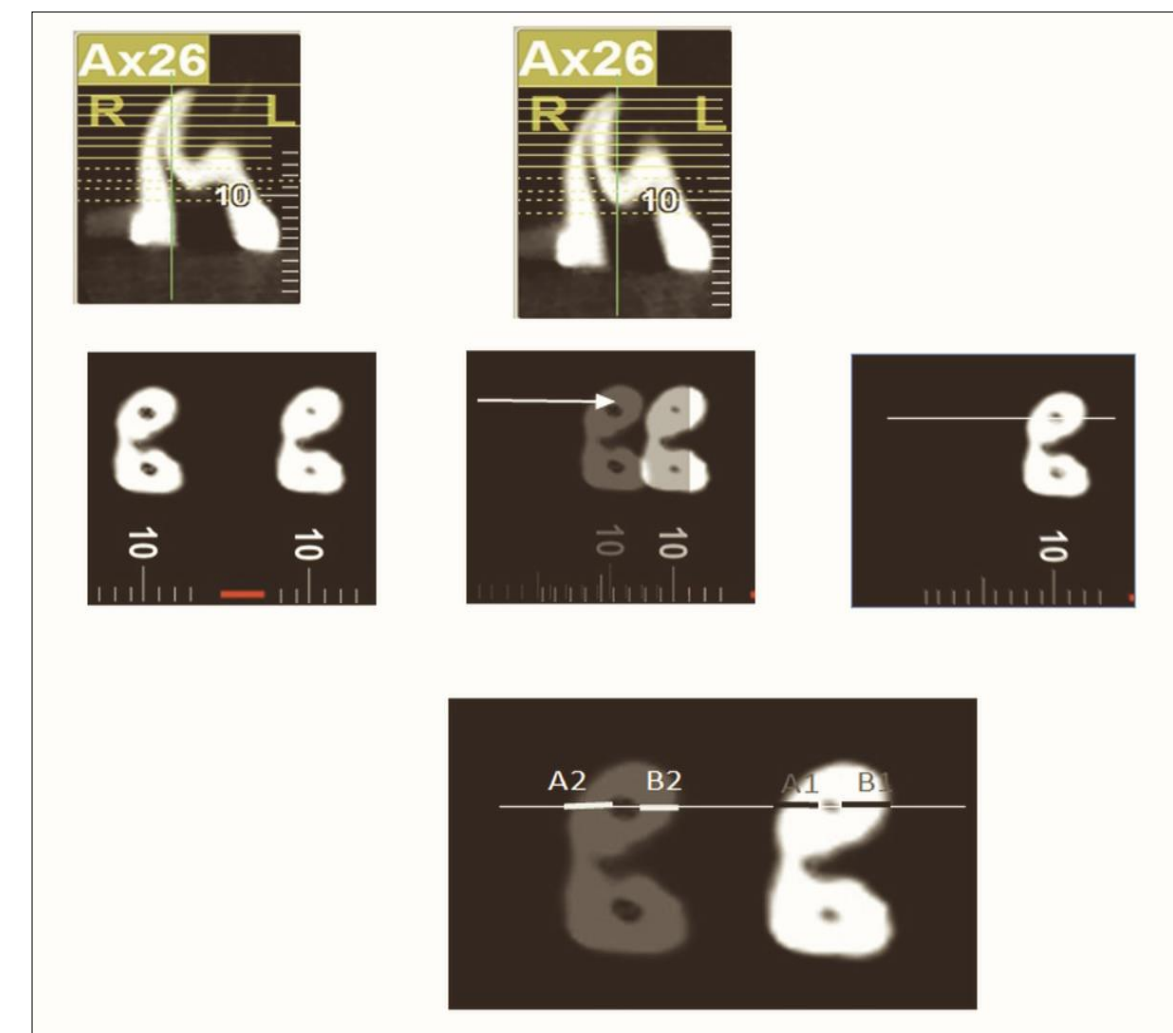

Figure 1. CBCT evaluation. Upper panel: Scanning at 9 different levels preoperator and postoperator: middle panel: cross-sectional CT images and thick arrow indicates direction of superposition result; lower panel:

CT image of tooth sections showing how transportation and centering ratio were derived

The following parameters were assessed after measurements on cross-sectional CBCT images: the centering ability, diameter change, canal transportation.

Centering ability and canal transportation was calculated according to Gambill et al.[13] formula:

$$
\text { (A1-A2) / (B1-B2) or (B1-B2) / (A1-A2), }
$$

a result of " 1 " indicates perfect centering, respectively

$$
\text { (A1-A2) - (B1-B2), }
$$

a result of "0" indicates no canal transportation. 
The pre and post-surgical diameter differences were assessed using the following formula:

$$
\{(\mathrm{A} 1-\mathrm{A} 2)+(\mathrm{B} 1-\mathrm{B} 2)\}
$$

The time taken for each preparation and the working length for each tooth, before and after instrumentation was recorded.

The statistical analysis used was ANOVA (Bonferroni and Tamhane tests) with the level of statistical significance set at $5 \%$.

\section{Results and discussions}

None of instruments had significant differences of their centering ability $(P \geq 0.05)$ maintaining the original canal curvature well. However, at $7 \mathrm{~mm}$ distance to apical foramen, Reciproc showed greater straightening of canal curvature than WaveOne $(P<0.05)$ and One Shape $(P<0.05)$ (Table 3$)$.

Tabel 3. Mean of centering ability and SD of canal preparation with the three different instruments $(n=15)$

\begin{tabular}{|c|c|c|c|c|c|c|}
\hline & Canal & $1 \mathrm{~mm}$ & $3 \mathrm{~mm}$ & $5 \mathrm{~mm}$ & $7 \mathrm{~mm}$ & $9 \mathrm{~mm}$ \\
\hline Instrument & Mean \pm SD & Mean \pm SD & Mean \pm SD & Mean \pm SD & Mean \pm SD & Mean \pm SD \\
\hline Wave One & $1.32 \pm 0.61$ & $1.5 \pm 1.5$ & $1.05 \pm 1.13$ & $1.12 \pm 1.5$ & $1.93 \pm 2.09$ & $1.21 \pm 1.01$ \\
\hline Reciproc & $1.30 \pm 0.23$ & $1.21 \pm 1.06$ & $1.86 \pm 2.08$ & $1.31 \pm 1.07$ & $2.57 \pm 2.48$ & $1.26 \pm 0.95$ \\
\hline One Shape & $1.23 \pm 0.53$ & $1.19 \pm 1.24$ & $1.38 \pm 1.22$ & $1.29 \pm 2.24$ & $0.41 \pm 0.37$ & $1.16 \pm 1.84$ \\
\hline
\end{tabular}

There was no significant difference between the 3 instruments with respect to the canal path (canal transportation) $(P \geq 0.05)$. In the section made within $1 \mathrm{~mm}, 3 \mathrm{~mm}, 5 \mathrm{~mm}, 7 \mathrm{~mm}$ of the root canal there was no significant difference in canal transportation between the 3 instruments (Table 4). In almost all sections of the root canal and for all shaping techniques, the mean degree of canal transportation was different from 0 .

Tabel 4. Mean of canal transportation ( $\mathrm{mm}$ ) after canal preparation with the three different instruments $(n=15)$

\begin{tabular}{|c|c|c|c|c|c|c|}
\hline & Canal & $1 \mathrm{~mm}$ & $3 \mathrm{~mm}$ & $5 \mathrm{~mm}$ & $7 \mathrm{~mm}$ & $9 \mathrm{~mm}$ \\
\hline Instrument & Mean \pm SD & Mean \pm SD & Mean \pm SD & Mean \pm SD & Mean \pm SD & Mean \pm SD \\
\hline Wave One & $0.208 \pm 0.08$ & $0.18 \pm 0.20$ & $0.16 \pm 1.13$ & $0.25 \pm 0.14$ & $0.22 \pm 0.22$ & $0.20 \pm 0.14$ \\
\hline Reciproc & $0.195 \pm 0.07$ & $0.14 \pm 0.10$ & $0.15 \pm 0.14$ & $0.22 \pm 0.24$ & $0.21 \pm 0.16$ & $0.19 \pm 0.11$ \\
\hline One Shape & $0.205 \pm 0.52$ & $0.14 \pm 0.11$ & $0.13 \pm 0.10$ & $0.18 \pm 0.12$ & $0.29 \pm 0.17$ & $0.17 \pm 0.15$ \\
\hline
\end{tabular}

The highest increase in diameter of the canal was observed for Wave One Primary which was not statistically significant for the entire canal $(P>0.05)$. However, in the last $4 \mathrm{~mm}$ of the canals we found a statistically significant difference between Wave One and Reciproc $(P<0.05)$ and One Shape $(P<0.05)$ (Table 5). 
Table 5. Mean of diameter change after canal preparation and time of canal preparation (min.) with three different instruments $(\mathrm{n}=15)$

\begin{tabular}{cccc}
\hline Instrument & Mean \pm SD & Mean in $4 \mathrm{~mm}$ apical \pm SD & Preparation time (min) \pm SD \\
\hline Wave One & $0.53 \pm 0.10$ & $0.67 \pm 0.18$ & $4.30 \pm 1.85$ \\
Reciproc & $0.44 \pm 0.11$ & $0.51 \pm 0.20$ & $3.33 \pm 1.43$ \\
One shape & $0.48 \pm 0.07$ & $0.54 \pm 0.17$ & $4.78 \pm 2.73$ \\
\hline
\end{tabular}

Instrumentation with Reciproc was faster than with One Shape and Wave One,but the differences were not statistically significant $(\mathrm{P}>0.05)$.

Change of working length ranged between 0 and $1 \mathrm{~mm}$.

During the preparation of the canals no instrument was fractured.

In the present study, we have evaluated and compared the preparation of curved canals of extracted molars with three single-file Reciproc R25, Wave One Primary and One Shape using CT imaging. To ensure comparability of the three groups the teeth were balanced with respect to the degree of canal curvature based on the initial radiograph.

For our investigation, we used the Reciproc R25 file, Wave One Primary file and One Shape file, with a 25-diameter tip, indicated for narrow and curved canals. There are rotary single systems that have been developed to reduce the duration of canal preparation and avoid the risk of crosscontamination.

The comparison of endodontic instrumentation using CBCT is an accurate method to investigate the efficiency of shaping techniques $[13,15,16]$. The difficulty of using CBCT to compare the anatomic structure of root canals before and after instrumentation lies in the need to have the same positioning of teeth in the unit for the two scans and the same cross-section level for the CBCT images of the un-instrumented and instrumented canal. In this study, we determined the changes of the wall size of root canal after instrumentation by drawing a vertical line from the same reference point on images performed before and after instrumentation. Horizontal sections were made perpendicular to this vertical line. Our goal was to get a picture that accurately reproduces the tooth size with welldefined edges to restore the tooth and the channel to be measured correctly. By changing the viewing parameters, we can obtain images that show teeth with different degrees of density to see the details more accurately.

Besides the differences between the instruments regarding their centering ability and canal transportation, this study also compared the changes of diameter and the time for preparation using different systems.

For the success of the endodontic treatment, it is essential to perform a high quality cleaning and sealing of the apical third of the root canal. If the apical portion of the root canal is not completely obturated, the residual bacteria may multiply and cause an endodontic failure [17]. The tissue fluids percolating into the apical root canal may provide a real nutrition environment for bacteria multiplication. Leakage occurs more frequently when the apical transportation index is $>0.3 \mathrm{~mm}$ [18].

In this study, two different types of motion, reciprocating and continuous, were used for the root canal cleaning. The results show that the apical transportation for all groups was lower than $0.2 \mathrm{~mm}$ with no significant difference between the three groups, being in agreement with the findings of previous studies [19]. According to this author, these results were due to the noncutting tip of these instruments, which function only as a guide in canal penetration. The lowest transportation canal in the apical third (1-3mm) was found for One Shape system followed by Reciproc and WaveOne. The results are in agreement with those of previous study by Saleh et al. [20] who suggested that less tapered instruments produce less canal transportation compared with more tapered instruments. The 
Reciproc and WaveOne show a taper of 08 over the first $3 \mathrm{~mm}$ from the tip whereas One Shape is characterized by a taper of 06 that provides more flexibility.

Comparing the same systems used in our study, Burklein et al. [12] and Saber et all [21] showed a significantly greater straightening and apical transportation for OneShape file than WaveOne and Reciproc. In study of Burklein apical transportation was $0.4 \mathrm{~mm}$ and the authors argue that the clinical relevance remains questionable. Nevertheless, since the maximum difference in apical transportation observed in our study was $0.2 \mathrm{~mm}$, we can conclude that all three instruments maintained the canal curvature.

The centering ability is the ability of a system to respect the trajectory of a root canal. An ideal instrumentation would have equal dentine removal from the canal walls, which is an indication of the safety of the instruments for preparing curved root canals [22]. The previous studies indicate that maintaining the original canal shape and curvature after instrumentation will increase the success rates and prognosis of the endodontic treatment[3].Several studies showed that more flexible instruments produce more centered preparation [15, 23]. The flexibility of NiTi files is depended on the structure of their alloy. Reciproc and Wave One are NiTi files manufactured by thermal treatment (M-wire) that possess certain amount of martensite or R-phase structure at room temperature which contributes to the enhanced flexibility of those instruments, due to lower Young's modulus compared to conventional NiTi alloy (One Shape). [24]It has also been demonstrated that the reciprocating motion and M-wire alloy provides excellent centering action, despite the use of a 0.8 tapered instrument [2].

In this study, centering ability for all groups at all levels was slightly greater or less than ratio 1. One Shape showed the best centering in the canal but the difference between the systems is not statistically significant. This signifies that One Shape has a good flexibility that allows it to follow the canal trajectory. These results are consistent with those obtained by Dhingra A et al. [23] that compare canal curvature modifications after instrumentation with One Shape and Wave One in simulated canals. In another study conducted by Gergy R [15] there was no significant difference in centering ration between Reciproc and Wave One. The lowest ratios for all systems were found in the apical part of the canal (up to $1 \mathrm{~mm}$ for One Shape and Reciproc and up to $3 \mathrm{~mm}$ for Wave One). The highest ratios were found at a $7 \mathrm{~mm}$ distance from the apex for all systems. This corresponds with the canal straightening in the coronal part.

Preparation time could be influenced by the technique, the number and type of the instruments used and the operator experience [3]. In the present study, the preparation time included active instrumentation, cleaning the flutes of the instruments, irrigation and check of patency, to allow comparison of the results with those of previous studies conducted with an identical experimental setup [2,11,12]. All procedures were performed by an experienced operator in order to exclude the possible influence of operator experience on the results. We found no significant difference in the instrumentation time between the three rotational systems. However, the instrumentation with Reciproc was faster than with One Shape and Wave One but these differences were not statistically significant $(p \geq 0.05)$. These results are in agreement with previous studies which used Reciproc and Wave One (11), Reciproc and One Shape [12] and the reports of Goldberg [11], that used Wave One for the experienced operator group.

Diameter changes depend on the volume of dentin removed by the instruments. This is important because dentin removal of more than the detection limit of microorganism's penetration $(80-150 \mu \mathrm{m})$ might be considered desirable to optimize canal disinfection [24]. In our study the diameter of the canal was greater, but not significantly, for the canals instrumented with Wave One than with One Shape and Reciproc. The results are consistent with those obtained by Versiani et al. [9] why explain these results by differences in cross-sectional designs and taper of instruments.Furthermore, disinfection by mechanical and chemical means in the apical area is considered the most predictive for successful of endodontic therapy because microorganisms remaining in this area are the main cause for failing endodontic therapy [25-27]. In our study, the diameter of the canal in the last $4 \mathrm{~mm}$ was 
increased with a mean of $0.67 \mathrm{~mm}$ for Wave One, $0.54 \mathrm{~mm}$ for One Shape and $0.51 \mathrm{~mm}$ for Reciproc. These results show an adequate enlargement of the canal in this region.

\section{Conclusions}

Within the limits of the present study it can be concluded that all systems perform safe and proper canal preparations. One Shape instrument,made of conventional NiTi, presented the same efficiency in root canal preparation when compared with the other two systems manufactured by thermomechanical treatment NiTi alloy, concerning analyzed parameters (centering ability, canal transportation, changes of diameter and time for preparation). Reciproc required the shortest time for canal instrumentation while WaveOne led to the greatest increase of canal diameter.

\section{References}

1.BERUTTI, E., GHIANDUSSI, G., PAOLINO, D.S., SCOTTI, N., CANTATORE, G., CASTELLUCCI, A., PASQUALINI, D., J Endod. 38, 2012, p. 505

2.GOLDBERG, M., DAHAN, S., MACHTOU, P., Int.J.Dent. 2012, 2012, 206521

3.SCHAFER, E., BURKLEIN, S., Odontology, 100, 2012, p.130

4.YARED G., Int Endod J., 41, 2008; p.339

5.YARED, G., 2011, www.endodonticcourses.com[accessed on November 2013], p.1

6.GUTMANN, J.L., GAO, Y., Int Endod J., 45, 2012, p.113

7.RUDDLE, C., Dentistry Today, 2012, January, p. 15

8.PEDULLA, E., GRANDE, N.M., PLOTINO, G., GAMBARINI, G., RAPISARDA, E., J Endod., 39, 2013, p.258

9.VERSIANI, M.A., LEONI, G.B., STEIER, L., DE-DEUS, G., TASSANI, S., PECORA, J.D., SOUSA-NETO, M.D., J Endod., 39, 2013, P. 1060

10.GERMHARDT, C.R., ENDO (Lond Engl), 7, 2013, p. 211

11.BURKLEIN, S., HINSCHITZA, K., DAMMASCHKE, T., SCHAFER, E., Int Endod J., 45, 2012, p.449

12.BURKLEIN, S., BENTEN, S., SCHAFER, E., Int Endod J., 46, 2013, p. 590

13.GAMBILL, J.M., ALDER, M., DEL RIO, C.E., J Endod., 22, 1996, p. 369

14.SCHNEIDER, S.W., Oral Surg Oral Med Oral Pathol Oral Radiol., 32, 1971, p. 271

15.GERGI, R., ARBAB-CHIRANI, R., OSTA, N., NAAMAN, A., J Endod.,40, 2014, p. 1223

16.TASDEMIR, T., AYDEMIR, H., İNAN, U., ÜNAL, O., Int Endod J., 38, 2005, p. 402

17.NAIR, P.N.R., SJOGREN, U., KREY, G., KAHBERG, K-E., SUNDQVIST, G., J Endod., 16, 1990, p. 80

18.WU, M.K., FAN, B., WESSELINK, P.R., J Endod., 25, 2000, p. 210-16

19.CAPAR, I.D., ERTAS, H., OK, E., ARSLAN, H., ERTAS, E.T., J Endod., 40, 2014, p. 852

20.SALEH, A.M., GILANI, P.V., TAVANAFAR, S., SHAFER, E., J Endod.,41, 2015, p. 548

21.SABER, S.E.D.M., NAGY, M.M., SCHAFER, E., Int Endod J., 48, 2015, p. 109

22.NAGAJARA, S, SREENIVASA MURTHY, B.V., J Conserv Dent., 13, 2010, p. 16

23.LOPES H.P., GAMBARRA-SOARES T., ELIAS C.N., SIQUEIRA J.F.Jr., INOJOSA I.F.J., LOPES W.S.P., VIEIRA V.T.L., J Endod., 39, 2013, p. 516

24.OH S., KUM K-Y. CHO K., LEE S-H., YOU S-H., GO J., JEON B-K., KIM S-W., KIM T-H., JANG J-H., PERINPANAYAGAM H., KIM J-W., CHANG S W. Biomed Res Int., 7, 2019, p. 4 25.DHINGRA, A., KOCHAR, R., BANERJEE, S., SRIVASTA, P., J Conserv Dent., 17, 2014, p. 138 26.PAQUE, F., GANABL, D., PETERS, O.A., J Endod., 35, 2009, p. 1056

27.NAIR, N.P., Int Endod J., 39, 2006, p. 249

Manuscript received: 25.05 .2020 